\title{
Effect of using GeoGebra software on students' achievement at university level
}

\author{
Ganesh Prasad Adhikari \\ Central Department of Mathematics Education \\ Tribhuvan University, Kathmandu, Nepal \\ gpadhikarin@gmail.com
}

\begin{abstract}
This study examined the effect of using GeoGebra software on students' achievement in the case of limit concepts at university level. The instruments used in this study were GeoGebra software, traditional teaching method, and Mathematics Achievement Test (MAT) taken to get the required information. A quasi-experimental design was used and the GeoGebra software introduced in teaching of the limit concept of Complex Analysis among twenty-nine students of section B and traditional teaching method introduced among thirty-one students of section A of the second semester of Master's in Mathematics Education. After the pre-test, the control group students had been taken the limit concept and related problem in a traditional method and the experimental group students toughed the same content with interactive worksheets by using GeoGebra software. After five hours of lecture in both groups, the standardized MAT (2) was applied for the post-test to the students of both groups. The gathered quantitative data were analyzed by using SPSS 26 version of the scores of sixty students on both groups. As a result, the findings of the research showed that the pre-test scores of students in both groups were insignificant differences. But the pretest and post-test scores of students in the experimental group and post-test scores of students in both groups were significant differences. The result showed that students were found more interactive in teaching through GeoGebra software and have a positive effect on students' achievement on the limit concept.
\end{abstract}

Keywords: GeoGebra, limit concept, students' achievement, conceptual understanding

\section{Introduction}

The concept of limit is one of the most fundamental and important assumptions not only in understanding calculus but also in developing mathematical thinking beyond calculus and in pursuing mathematical rigor (Ferrini-Mundy \& 
Lauten 1993; Tall 1992). It establishes a framework necessary to have a complete acquisition of the basic concepts of calculus such as continuity, differentiation, and integral. Therefore, the limit concept should have been the focus of various research studies. The mathematical concept of the limit holds a central position in mathematical analysis as a foundation of the theory of approximation, continuity and differentiability of differential calculus, integral calculus and complex analysis (Cornu, 1991). He believes that this mathematical concept is a particularly difficult idea, typical of the type of thinking required in advanced mathematics. Due to the above-mentioned importance of limit, a considerable amount of research has been conducted on this concept. Most of the research revealed that students face problems while learning limit concept in their courses (Williams, 1991). The misconceptions of limit not only affect the understanding of limit itself but also cause difficulties in subsequent topics such as continuity and differentiability of functions (Bezuidenhout, 2001; Cornu, 1991) and an infinite series (Sierpińska, 1987). According to Davis and Vinner (1986), the crucial role of learning the limit concept in students' success in calculus as the findings of their study indicated a deficiency in learning the limit concept. Also, the main reason for the difficulties encountered by students in learning continuity, differentiation, and integration is the deficiency in learning limit concept (Bezuidenhout, 2001). The difficulties experienced regarding limit showed that students are able to use the application of limit up to some point but they have difficulty in the stage of constructing the concept of limit (Cottrill et al., 1996). On the other hand, it was said that possible types of problems related to limits of functions are: to calculate the limit of a function, to demonstrate the existence of a limit, to define the notion of limit of a function, to check the validity of proof, etc. (Barbé et al., 2005). The comments on 'formal limit' definition points out 'Students do not have a conception of quantification which is sufficiently powerful to deal with the formal limit concept.' Juter (2006) in her study on the limit states: Teachers at universities must be aware of how students have created their early conceptions of limit and infinity, and try to offer opportunities to develop these, often limited and insufficiently matured, conceptions to more meaningful concepts.

According to NCTM (2000), Information and Communication Technology (ICT) is essential powerful resources in teaching and learning mathematics. It makes easy to understand new concepts, knowledge, skill related to daily life circumstances. The system of education has been affected by technology. New technologies challenge traditional designs and ensuring new concepts in the teaching-learning process and it can influence the mathematics that is taught and enhances students' 
learning. Besides that, technology can also help students to furnish their visual images of mathematical ideas, organizing and analyzing data, and can compute efficiently and accurately. Technology can support students to investigate in every area of mathematics, such as geometry, statistics, algebra, measurement and calculus (NCTM, 2000).

In Nepal, the concept of limit is also taught for students who take the extra (optional) mathematics subject at secondary and university levels. Learning limit concept may not be easy and a large number of students fail to develop an adequate understanding, reasoning, and problem solving skill in it. According to Winarso and Toheri (2017), the lack of understanding in learning limit often causes discouragement among the students, which invariably will lead to poor performance in calculus and claimed that some factors have been identified causing the difficulties in learning limit. Those are the teaching materials used by teachers, classroom management, content knowledge, geometry language, visualization abilities and teaching methods. The concept of limit can be considered a difficult subject. In the typical classroom, the challenge for students is to explore complex problems. With the advancement of multimedia technology, learning difficulties can be overcome. The challenge is more complex in teaching and learning mathematics, where teachers need to balance mental, stationery, and digital tools for teaching and learning that involve abstract mathematical concepts that are difficult for students to understand (Prieto, Sordo Juanena \& Star, 2013). Technology plays an important role in the improvement of the educational process and performance (Cetin, 2009).

Many types of research studies have been done to develop teaching methods that support the visualization of the rigorous concept of limit; thus helping the students to take the clear concept and determine the limits with precision as well as to use correctly the rigorous definition of the limit (Cottrill et al., 1996). There were also different hypotheses of dynamic images as to the causes of the difficulties encountered by the students to learn the rigorous concept and the definitions of the limit. For example, Tall and Vinner (1981) and Williams (1991) hypothesis that once students have absorbed the dynamic image of limits from their prior learning, this image may interfere with understanding the rigorous definition of the limit. On the other hand, Cottrill et al. (1996) suggest that students develop their ability to grasp the dynamic image of boundaries in order to understand precisely the rigorous definition of the boundary. In addition, Kidron and Zehavi (2002) affirm the effectiveness of dynamic images in learning the concept of limit and suggest computer animation as a powerful visual interpretation of the dynamic image of 
limits. The study by Pinto and Tall (2002) also revealed that visual images play a positive role in teaching and learning about real analysis. Likewise, Navarro and Carreras (2006) have shown that a visual pedagogical method would not only help students build a relevant conceptual image of boundaries, but it would also help students move towards a more rigorous mathematical definition. A number of studies have demonstrated that technology has an important potential to develop spatial skills. Travis and Lenon (1997) used MAPLE, a software package with graphics capabilities to improve spatial skills, and found that students in the experimental class performed better on the spatial skills test. In another research, Hodanbosi (2001) used Geometer's Sketchpad (GSP), dynamic geometry software that found that students in the GSP group had significantly higher achievement scores on the Geometry Achievement Test than students in the traditional group.

There are various types of mathematical software available to facilitate to teaching and learning mathematics, for example, Geometer's Sketchpad, Derive, Cabri, Matlab, Autograph, GeoGebra, Mathematica and others. These mathematical softwares have been used in school and university levels worldwide. Teachers need to purchase those software in order to use it in the classroom, but some of the software is costly. However, Geogebra software is freely available and used by educators in classroom teaching. Several studies have been carried out on GeoGebra software to study different aspects of learning and practicing a teaching tool that can help teachers to design effective teaching lessons in the developed country, but developing countries may have difficulties due to financial difficulties, awareness, availability, appropriate policies and integration issues. Nepal is a developing country for technological or digital dives are not very developed (Joshi, 2016). The evolution in using technology in teaching and learning process has grown by leaps and bounds. The use of GeoGebra software is important because it serves as an educational object, which affects learning content and objectives, and as a means of improving the teaching and learning process (Arbain \& Shukor, 2015), GeoGebra has been shown to improve the effectiveness of meaningful learning and conceptual understanding of intended mathematics topics of students. In addition, mathematics education researchers have shown that the effective use of GeoGebra supports and has a positive impact on abstract understanding and success in a wide variety of mathematics topics including geometry (Saha et al., 2010), and calculus (Zulnaidi et al., 2018).

Thus, from the above several studies, the use of ICT in teaching mathematics has demonstrated positive effects on students' achievement, a reading of the 
literature available indicates that many of these studies are not centered on GeoGebra instructional approach in teaching and learning limit concept at higher level, particularly in Nepal. Also, the findings of the study pointed the challenges teachers faced in teaching limit due to lack of resources to teach it, its abstract nature and inability of students to visualize geometrical images. Therefore, it is the aim of this study to determine the effect of GeoGebra software on students' achievement: the case of limit concept at university level students. This will enable students visualize limit concept in GeoGebra interface and discover properties about it.

Analyzing the above research works some questions arise in the mind of the researcher:

1. What is the effect of GeoGebra software integration in limit concept at master's level students' achievement in contrast to the traditional method?

2. Is there any significant gender difference in students' achievement when taught limit concept using by GeoGebra software?

Thus, the researcher has tried to find out the answer of the above questions. Therefore, the present study is an attempt to know the effect of using GeoGebra software on students' achievement in limit concept at master's level students' at University Campus, Kirtipur Kathmandu, Nepal.

\section{Objectives of the Study}

This study was carried out in order to analyze the effect of using GeoGebra software about the students' achievement in limit concept at University Campus, Kirtipur, Kathmandu, Nepal. Therefore, the following research objectives were purposed:

1. To determine differences in mean between pretest and posttest scores of the experimental and control group students

2. To determine difference in mean between posttest scores of the experimental and control group students

\section{Research Hypothesis}

The following null hypotheses were raised to guide the study:

- $\mathrm{Ho}_{1}$ : There is no significant difference in the mean between pre-test scores of the experimental and control group students.

- $\mathrm{Ho}_{2}$ : There is no significant difference in mean between pre-test and post-test scores of the experimental group students.

- $\mathrm{Ho}_{3}$ : There is no significant difference in the mean between pre-test and post-test 
scores of the control group students.

- $\mathrm{H}_{04}$ : There is no significant difference in the mean between post-test scores of the experimental and control group students.

- $\mathrm{Ho}_{5}$ : There is no significant gender difference in the mean of post-test scores of the experimental group.

\section{Methodology}

This study was conducted by using a non-equivalent pre-test and post-test quasi-experimental design because it provide the best approach to investigating cause and effect relationships (Cohen, Manion, \& Morrison, 2012). The target population for this study was all second semester students of 2019 in the University Campus, Kirtipur, Nepal. The sample of this study consisted of 60 students at which 29 were in section A and 31 were in section B. The purposive sampling technique was used to select section A as experimental group and section B as control group. The experimental group was taught the limit concept by using GeoGebra software. Meanwhile, the control group was taught the limit concept by traditional method. The instruments used for this study were two sets of Mathematics Achievement Test (MAT) for pre-test and post-test. Each instrument contained 10 objective and 4 subjective questions prepared by the researcher to measure the students' achievement in knowledge, comprehensive and application level of limit concept prescribed by syllabus of Complex and Numerical Analysis. The use of different test elements during the pre-test and post-test of a test instrument eliminates bias in the scores (Creswell, 2012). The content validity of the pre-test and post-test was examined by its approval from the mathematics education experts (Professor from Tribhuvan University Central Department), mathematics teachers and exporters. It has been revised on the basis of feedback from exports. Then, the researcher used the Content Validity Index (CVI) to determine whether the item was valid or not. The CVI for items was calculated as the proportion of experts. The items with a CVI greater than 0.79 remained (Davis, 1992) and the rest were discarded. For the reliability of the pre-test and post-test, the researcher carried out pilot study of the test prepared. 18 students of Mahendra Ratna Campus, Tahachal Kathmandu were used for pilot study. The instrument's correlation coefficient was 0.81 , which is acceptable for the application.

The teaching material used for this study consisted of a lesson plan based on the limit concept of Complex Analysis. This study adopted three phases. In the 
first phase, pre-test was administered to both groups students' for the purpose of the knowing the knowledge of limit concept by the first set of MAT (1) before treatment. In the second phase, researcher spent only five hours for treatment. The experiment group was taught the limit concept using GeoGebra while the control group was taught utilizing traditional teaching method. In the final phase, post-test was administered to both groups at the end of the treatments by second MAT (2) and t-test was used to test the statistical significant difference between the experimental and control groups. All analyses were conducted using SPSS 26 version. The statistical significance level was set at $\mathrm{p}<0.05$.

\section{Results}

\section{$\mathrm{Ho}_{1}$ : There is no significant difference in the mean between pretest scores of the experimental and control group students}

\section{Table 1}

Analysis of Mean Scores of Pre-test for Experimental and Control Groups

\begin{tabular}{|l|l|l|l|l|l|l|}
\hline Groups & N & Mean & SD & t-value & Sig.(2-tailed) & Result \\
\hline Experimental & 29 & 16.10 & 3.48 & 1.12 & 0.27 & $1.12<1.96$ \\
\hline Control & 31 & 15.16 & 3.06 & & & \\
\hline
\end{tabular}

Insignificant at 0.05 level

$\mathrm{N}=$ Number of Students

$\mathrm{M}=$ Mean, $\mathrm{SD}=$ Standard Deviation d.f. $=\mathrm{N}_{1}+\mathrm{N}_{2}-2=29+31-2=58$

Tabulated Value $\left(\mathrm{t}_{0.05,58}\right)=1.96$ ( two tailed test)

The analysis of the information mentioned in Table 1 represents that in the experimental group there were 29 students and in control group, there were 31 students of second semester at mater's level at University Campus Kirtipur. The mean score obtained by students of experimental group was 16.10 and standard deviation (SD) was 3.48. Similarly, in the control group, the mean score of the students was 15.16 and standard deviation (DS) was 3.06. Therefore, the mean score of mathematics students of the experimental group was higher than the mean score students of the control group by 0.94 since the calculated t-value was 1.12 which is less than the tabulated value $\mathrm{t}_{0.05,58}=1.96$ and $\mathrm{p}$-value was 0.27 . Hence, this difference in mean is insignificant at 0.05 levels. It indicates that there is no difference between the mean score of mathematics students of the experiment group and control group. Therefore, our null hypothesis "There is no significant difference 
in the mean between pretest scores of the experimental and control group students" is accepted. From the mean scores, the researcher concludes that the pre-test scores of experimental and control groups were the same.

\section{$\mathrm{Ho}_{2}$ : There is no significant difference in the mean between pretest and posttest scores of experimental groups}

Table 2

Analysis of Mean Scores of Pre-test and Post-test for Experimental Groups

\begin{tabular}{|l|l|l|l|l|l|l|}
\hline Tests & N & Mean & SD & t-value & Sig.(2-tailed) & Result \\
\hline Pre-test & 29 & 16.10 & 3.48 & -8.88 & .00 & $-8.88<-1.96$ \\
\hline Post-test & 29 & 23.03 & 2.89 & & & \\
\hline
\end{tabular}

Significant at 0.05 level

$\mathrm{N}=$ Number of Students

$\mathrm{M}=$ Mean, $\mathrm{SD}=$ Standard Deviation d.f. $=\mathrm{N}_{1}+\mathrm{N}_{2}-2=29+29-2=56$

Tabulated Value $\left(\mathrm{t}_{0.05,56}\right)=1.96$ ( two tailed test)

The analysis of the information mentioned in Table 2 represents that the total number of students in pre-test was 29 and post-test was 29 in the experimental group. The mean score of pre-test was 16.10 and Standard deviation (SD) was 3.48. Similarly, the mean score of post-test was 23.03 and standard deviation (DS) was 2.89. Therefore, the mean score of post-test was higher than the mean score of pre-test of experimental group students by 6.93. Since the calculated t-value was -8.88 which is less the than tabulated value $t_{0.05,58}=-1.96$ and $p$-value was 0.00 , this difference in mean is significant difference at 0.05 levels. It indicates that there is different between the mean score of pre-test and post-test of experimental group students. Therefore, our null hypothesis "There is no significant difference in the mean between pretest and posttest scores of experimental groups" is rejected. From these mean scores, the researcher concludes that the GeoGebra software enhanced the achievement of the experimental group students.

\section{$\mathrm{Ho}_{3}$ : There is no significant difference in the mean between pre-test and post- test scores of control group}

Table 3

Analysis of Mean Scores of Pre-test and Post-test for Control Groups

\begin{tabular}{|l|l|l|l|l|l|l|}
\hline Tests & N & Mean & SD & t-value & Sig.(2-tailed) & Result \\
\hline Pre-test & 31 & 14.84 & 2.56 & 0.76 & 0.46 & $0.76<1.96$ \\
\hline Post-test & 31 & 14.68 & 1.82 & & & \\
\hline
\end{tabular}


Insignificant at 0.05 level

$\mathrm{N}=$ Number of Students

$\mathrm{M}=$ Mean, $\mathrm{SD}=$ Standard Deviation d.f. $=\mathrm{N}_{1}+\mathrm{N}_{2}-2=31+31-2=60$

Tabulated Value $\left(\mathrm{t}_{0.05,60}\right)=1.96$ ( two tailed test)

The analysis of the information mentioned in Table 3 represents that the total number of students in pre-test was 31 and post-test was 31 in the control group. The mean score of pre-test was 14.84 and Standard deviation (SD) was 2.56. Similarly, the mean score of post-test was 14.68 and standard deviation (DS) was 1.82. Therefore, the mean score of post-test was less than the mean score of pre-test of control group students by 0.16 . Since the calculated t-value was 0.76 which is less the than tabulated value $\mathrm{t}_{0.05,60}=1.96$ and $\mathrm{p}$-value was 0.46 , this difference in mean is insignificant difference at 0.05 levels. It indicates that there is no different between the mean score of pre-test and post-test of control group students. Therefore, the null hypothesis "There is no significant difference in the mean between pretest and posttest scores of control group students" is accepted. From these mean scores, the researcher concludes that the traditional teaching method does not enhance the achievement of the control group students.

\section{$\mathrm{H}_{04}$ : There is no significant difference in the mean between post-test scores of the experimental and control group students}

Table 4

Analysis of Mean Scores of Post-test for Experimental and Control Groups

\begin{tabular}{|l|l|l|l|l|l|l|}
\hline Groups & N & Mean & SD & t-value & Sig.(2-tailed) & Result \\
\hline Experimental & 29 & 23.03 & 2.89 & 13.49 & 0.00 & $1.96<13.49$ \\
\hline Control & 31 & 14.68 & 1.82 & & & \\
\hline
\end{tabular}

Significant at 0.05 level

$\mathrm{N}=$ Number of Students

$\mathrm{M}=$ Mean, $\mathrm{SD}=$ Standard Deviation d.f. $=\mathrm{N}_{1}+\mathrm{N}_{2}-2=29+31-2=58$

Tabulated Value $\left(\mathrm{t}_{0.05,58}\right)=1.96$ ( two tailed test)

The analysis of the information mentioned in Table 4 represents that in the experimental group there were 29 students and in control group, there were 31 students. The mean score obtained by students of experimental group was 23.03 and standard deviation (SD) was 2.89. Similarly, in the control group, the mean score of the students was 14.68 and standard deviation (DS) was 1.82. Therefore, the mean score of the experimental group students was higher than the mean score of the control group students by 8.35 . The calculated t-value was 13.49 which is higher 
than the tabulated value $\mathrm{t}_{0.05,58}=1.96$ and $\mathrm{p}$-value was 0.00 . Hence, this difference in mean is significant at 0.05 levels. It indicates that there is different between the mean score of experiment group and control group students. Therefore, our null hypothesis "There is no significant difference in the mean between post-test scores of the experimental and control group students" is rejected. From the mean scores, the researcher concludes that the teaching approach affects in achievement of the students.

\section{$\mathrm{H}_{05}$ : There is no significant gender difference in mean of the post-test scores of experimental group students.}

Table 5

Analysis of Mean Scores of Post-test for Boys and Girls Students in the Experimental Groups

\begin{tabular}{|l|l|l|l|l|l|l|}
\hline Groups & N & Mean & SD & t-value & Sig.(2-tailed) & Result \\
\hline Boys & 19 & 24.00 & 2.26 & 2.75 & 0.01 & $2.05<2.75$ \\
\hline Girls & 10 & 21.20 & 3.19 & & & \\
\hline
\end{tabular}

Significant at 0.05 level

$\mathrm{N}=$ Number of Students

$\mathrm{M}=$ Mean, $\mathrm{SD}=$ Standard Deviation d.f. $=\mathrm{N}_{1}+\mathrm{N}_{2}-2=19+10-2=27$

Tabulated Value $\left(\mathrm{t}_{0.05,27}\right)=2.05$ ( two tailed test)

The analysis of the information mentioned in Table 5 represents that the post-test mean scores of boys was 24.00 and standard deviation (SD) was 2.26. Similarly, the mean score of girls was 21.20 and standard deviation (DS) was 3.19 in the experimental group students. Therefore, the mean score of boy students was higher than the mean score of girl students by 2.80 . Since the calculated t-value was 2.75 which is higher than the tabulated value $\mathrm{t}_{0.05,27}=2.05$ and $\mathrm{p}$-value was 0.01 , this difference in mean is significant at 0.05 levels. It indicates that there is different between the mean score of boys and girls in experiment group students. Therefore, the null hypothesis "There is no significant gender difference in mean of the post-test scores of experimental group students" is rejected. From the mean scores, the researcher concludes the achievement of boys is better than girls student in experimental group.

\section{Discussion}

In this study, the effect of using GeoGebra software on student's achievement in learning limit concept was examined using quasi-experimental design. This is 
indicated that mean scores of pre-test and post-test is significantly different in the experimental group (see Table 2), but the control group is insignificantly different (see Table 3). The findings regarding students' achievement using GeoGebra software in the experimental group are consistent with the finding of Shadaan and Eu (2013), and Tay (2018) was a valid strategy to help students achieve high academic standards in Mathematics Education. Also, using GeoGebra has no significant effect on the gender of students in experimental group (see Table 5) which is against the finding of Joshi (2016).

This finding shows that using the GeoGebra software in learning mathematics

lessons or classes has a very higher degree of success. As a result, GeoGebra software enhanced the mathematics achievement of students on abstract concept of mathematics. It is a powerful pedagogical tool that helps to understand abstract concept, contents and develops the necessary skills for solving the mathematical problems.

\section{Conclusion}

Based on the above discussion, the researcher came to the conclusion that the GeoGebra software is an essential and useful tool to improving students' engagement in learning activities, the abstraction and achievement in mathematics, in particular in learning the concept of limit at secondary and university levels. Learning and teaching this concept should not focus on purely theoretical aspects, but also on a variety of learning approaches that involve the use of proven teaching aids to stimulate student interest in mathematics. Mathematics software available on the market or even online has made it easier for the teacher to impart impartial knowledge beneficial to students. However, it depends on the teacher to use the existing material without needing to allocate additional time to develop other teaching aids.

Therefore, mathematics teachers and students should be recommended to use GeoGebra in their teaching and learning process at all levels. This software provides teachers and students with a new free tool, a new way to use technology with visual tool to help students interact with basic concept and abstraction of mathematics contents individually or in groups, in class or at home, or at most convenient location for the needs of teachers and students using computers. This tool can be used as complementary activities to the regular classroom, where students can get immediate feedback on their achievement, in classroom activities as well as in their homework. 


\section{References}

Arbain, N., \& Shukor, N. A. (2015). The effects of GeoGebra on students achievement. Procedia - Social and Behavioral Sciences, 172, 208-214. https://doi.org/10.1016/j.sbspro.2015.01.356

Barbé, J., Bosch, M., Espinoza, L., \& Gascón, J. (2005). Didactic restrictions on the teacher's Practice: The case of limits of functions in Spanish high schools. Educational Studies in Mathematics, 59(1-3), 235-268. https://doi. org/10.1007/s10649-005-5889-z

Bezuidenhout, J. (2001). Limits and continuity: Some conceptions of first-year students. International Journal of Mathematical Education in Science and Technology, 32, 487-500.

Cetin, N. (2009). The performance of undergraduate students in the limit concept. International Journal of Mathematical Education in Science and Technology, 40(3), 323-330. https://doi.org/10.1080/00207390802568119.

Cornu, B. (1991). Limits. In D. Tall (Ed.), Advanced mathematical thinking (pp. 153166). Dordrecht, the Netherlands: Kluwer Academic.

Cohen, L., Manion, L., \& Morrison, K. (2012). Research methods in education. In Professional Development in Education, 38 (3). https://doi.org/10.1080/1941 5257.2011.643130

Cottrill, J., Dubinsky, E., Nichols, D., Schwingendorf, K., Thomas, K., \& Vidakovic, D. (1996). Understanding the limit concept: Beginning with a coordinated process schema . In Appears in Journal of Mathematical Behavior, 15.

Creswell, J. W. (2012). Educational research: Planning, conducting and evaluating quantitative and qualitative research (4 ed.). Boston, MA: Pearson Education, Inc.

Davis, R. B., \& Vinner, S. (1986). The notion of limit: Some seemingly unavoidable misconception stages. The Journal of Mathematical Behavior, 5(3), 281-303.

Davis, L.L. (1992). Instrument review: Getting the most from a panel of experts. Applied Nursing Research, 5, 194-197.

Ferrini-Mundy,J., \& Lauten, D. (1993). Teaching and learning calculus, In P. S. Wilson (Ed.), Research ideas for the classroom: High school mathematics (pp. 155-176). New York: Macmillan. 
Hodanbosi, C. L. (2001). A comparison of the effects of using a dynamic geometry software program and construction tools on learner achievement, Unpublished Ph.D., Kent State University, United States .

Joshi, D. R. (2016). Status of use of ICT by secondary school students of Nepal. International Journal for Innovative Research in Multidisciplinary Field, 2(11), 256-262.

Juter, K. (2006). Limits of functions: University students' concept development (Doctoral dissertation, Luleå tekniska universitet).

Kidron, I., \& Zehavi, N. (2002). The role of animation in teaching the limit concept, The International Journal of Computer Algebra in Mathematics Education, 9, 205-227.

Navarro, M., \& Carreras, P.(2006).Constructing a concept image of convergence of sequences in the Van- Hiele framework. Research in Collegiate Mathematics Education, VI, 61-98.

NCTM, (2000). Curriculum and evaluation standards for school Mathematics, Reston, VA: NCTM Publications

Pinto, M., \& Tall, D. (2002). Building formal Mathematics on visual imagery, A case study and a theory. For the Learning of Mathematics, 22, 2-10

Saha, R. A., Fauzi, A., Ayub, M., \& Tarmizi, R. A. (2010). The effects of GeoGebra on Mathematics achievement: Enlightening coordinate Geometry learning. Procedia Social and Behavioral Sciences, 8, 686-693.https://doi. org/10.1016/j.sbspro.2010.12.095

Shadaan, P., \& Eu, L. K. (2013). Effectiveness of using Geogebra on students ' understanding in learning circles. The Malaysian Online Journal of Educational Technology, 1(4), 1-11.

Sierpińska, A. (1987). Humanities students and epistemological obstacles related to limits. Educational Studies in Mathematics, 18, 371-397.

Tall, D. (1992). The transition to advanced Mathematical thinking: Functions, limits, infinity, and proof. In D. A. Grouws (Ed.), Handbook of Research on Mathematics Teaching and Learning (pp. 495-511). New York: Macmillan.

Tall, D., \& Vinner, S. (1981). Concept image and concept definition in Mathematics, with particular reference to limits and continuity, Educational Studies in Mathematics, 12, 151-169. 
Tay, M. K. (2018). Effect of using Geogebra on senior high school students' performance in circle theorems. African Journal of Educational Studies in Mathematics and Sciences, 14(0), 1-18.

Travis, B., \& Lennon, E. (1997). Spatial skills and computer-enhanced instruction in calculus. J. Comput. Math. Sci. Teach., 16(4), 467-475.

Williams, S. R. (1991). Models of limit held by college calculus students.

Journal for Research in Mathematics Education, 22(3), 219. https://doi. org/10.2307/749075

Winarso, W., \& Toheri, T. (2017). A case study of misconceptions students in the learning of Mathematics: The concept limit function in high school. Jurnal Riset Pendidikan Matematika, 4(1), 120-127. https://doi.org/10.21831/jrpm. v4i1.12060

Zulnaidi, H., Oktavika, E., \& Hulu, K. R. (2018).The effect of Gegebra on students' misconceptions of limit function topic. Journal Kurikulum \& Pengajaran Asia Pasifik, 6(1), 1-6. juku.um.edu.my 